\title{
AGILITY SCRUM - Um Jogo para Ensino da Metodologia SCRUM
}

\author{
Ronney Moreira de Castro ${ }^{1,2}$, Sean Wolfgand Matsui Siqueira ${ }^{2}$, Denilson Novais de \\ Almeida ${ }^{1}$, Felipe Calegario Nascimento ${ }^{1}$ \\ ${ }^{1}$ Faculdade Metodista Granbery - Juiz de Fora (FMG) \\ Rua Batista de Oliveira, 1145 - Granbery - Juiz de Fora - MG - Brasil \\ ${ }^{2}$ Programa de Pós-Graduação em Informática (PPGI) \\ Universidade Federal do Estado do Rio de Janeiro(UNIRIO) \\ Av. Pasteur, 456 -Urca -Rio de Janeiro -RJ - Brasil \\ ronney.castroegranbery.edu.br, seanduniriotec.br, \\ denilsonalmeida.bj@gmail.com, felipe.calegarionascimento@gmail.com
}

\begin{abstract}
Considering the problems faced by the teachers and students in teaching and learning the Agile Scrum Methodology as a Software Engineering practice, this paper describes a different approach. A noncomputational game was developed and the students were able to have a practical experience on the use of this methodology, which in its turn brought a better acceptance, assimilation and result in the exercises and works done by the students. Thus, it presents a good use and efficacy in the application of the content proposed by teachers.
\end{abstract}

Resumo. Tendo em vista as dificuldades encontradas por docentes e discentes no ensino e no aprendizado da Metodologia Ágil Scrum como prática de Engenharia de Software, este artigo descreve uma abordagem diferente. A partir da criação de um jogo não computacional, os discentes puderam vivenciar uma experiência prática do uso da metodologia, o que por sua vez trouxe uma melhor aceitação, assimilação e resultado nos exercícios e trabalhos realizados, indicando assim um bom aproveitamento e eficácia na aplicação do conteúdo proposto pelos docentes.

\section{Introdução}

O Scrum é uma metodologia ágil para organizar e gerenciar projetos. Usa um processo onde, várias etapas devem ser seguidas, de forma a garantir a produção de determinado produto no prazo e no orçamento, e possui poucos artefatos e práticas, além de regras diretas e fáceis de aprender. Na área de Tecnologia da Informação (TI) é muito utilizado para o desenvolvimento de software [PEREIRA et al., 2007] [SCHWABER, 2004]. Em geral, essa metodologia é ensinada dentro da Engenharia de Software de forma predominantemente teórica, fazendo com que seu conteúdo não seja atrativo, pois não conta com uma vivência prática, por mais simples que ela seja [REIF e MITRI, 2005].

Aula expositiva é o método predominante usado pela maioria dos professores de Informática, particularmente em cursos introdutórios [GUDIGANTALA, 2013]. Entretanto, pesquisas anteriores sugerem que o uso exclusivo de aulas expositivas limita a aprendizagem dos alunos [BONWELL e EISON, 1991]. Por outro lado, o uso de práticas lúdicas auxilia no aprendizado do aluno e, com isso, jogos educativos vêm 
sendo desenvolvidos e utilizados para esta finalidade, aprimorando a comunicação entre o docente e discente [KAHL, 2007].

Nos cursos relacionados à área de computação tem-se observado que através da utilização dos jogos, o estudante absorve melhor os conceitos estudados e compreende as tomadas de decisões, simulando uma realidade que ele enfrentará no dia-a-dia quando estiver no mercado de trabalho [ROSSIOU e PAPADAKIS, 2007]. Seu uso é considerado uma estratégia poderosa, capaz de trazer benefícios para os alunos, tais como o aumento na eficácia da aprendizagem, um maior interesse pelas aulas, maior persistência e motivação [BATTISTELLA e WANGENHEIM, 2016]. Através do processo lúdico pode-se mostrar e ensinar de forma prática a importância do Scrum em diversas áreas de atuação e não apenas na área de Tecnologia [OLIVEIRA, 1999].

Considerando este cenário, foi projetado o Agility Scrum, que é um jogo educacional direcionado para o ensino de Scrum. O diferencial da abordagem aqui apresentada está em contemplar aspectos principais do Scrum, bem como situações do dia-a-dia de um projeto, que são simuladas utilizando práticas do Movimento Maker ${ }^{1}$, mais especificamente, componentes eletrônicos simples.

De modo a avaliar a eficácia do jogo e verificar se o objetivo central - ensinar a metodologia Scrum de uma forma prática (diferente das aulas expositivas tradicionais) foi atingido, o Agility Scrum foi aplicado em turmas do $6^{\circ}, 7^{\circ}$ e $8^{\circ}$ períodos do Curso de Bacharelado em Sistemas de Informação da Faculdade Metodista Granbery - Juiz de Fora - MG, em outubro de 2016. A dinâmica do jogo e os resultados da avaliação são apresentados no artigo.

O restante do artigo está organizado em mais cinco seções. Na seção 2 são apresentados os conceitos da metodologia Scrum e na seção 3 jogos para apoiar seu ensino. A seção 4 descreve o jogo Agily Scrum propriamente dito, os passos de sua preparação, assim como a forma utilizada para jogá-lo e sua aplicação nas turmas. Os resultados alcançados estão na seção 5 e, por fim, a conclusão do artigo na seção 6 .

\section{Scrum}

O Scrum conta com três papéis fundamentais: (i) Scrum Master - responsável por fazer a equipe respeitar as práticas do Scrum, além de ser o responsável por conduzir a Daily Meeting (Reunião Diária). Em geral este papel é exercido pelo gerente de projetos; (ii) Scrum Team - refere-se à equipe de desenvolvimento, onde podem ser encontrados desenvolvedores, analistas de testes e arquitetos de software, entre outros; e (iii) Product Owner - responsável por definir os itens que farão parte do Product Backlog, ou seja, as atividades que podem maximizar o trabalho da equipe de Scrum. É um papel representado por apenas uma pessoa, podendo ser um membro da equipe, ou até mesmo, o próprio cliente [SCHWABER e BEEDLE, 2002].

O processo do Scrum é iterativo e incremental. São feitas diversas entregas de versões funcionais durante o projeto, o que permite a constante inspeção do produto e evita desvios indesejados [SCHWABER, 2004]. Entretanto, não é um método formal e

\footnotetext{
${ }^{1}$ A ideia central desse movimento é proporcionar a experiência de fazer, construir coisas. Para isto, buscase possibilitar o acesso aos aprendizes a tecnologias como de manipulação de instrumentos, como máquinas de corte a laser, cortadoras de vinil, fresadoras, componentes eletrônicos diversos (leds, resistores, fios para ligações etc.) e, em alguns casos, impressoras 3D.
} 
padronizado e não fornece uma série de passos que garanta que, após sua aplicação, os objetivos do projeto serão atingidos [RUBIN, 2012].

O Product Backlog é um conceito considerado parte fundamental do Scrum. Consiste em uma lista de itens com prioridades que incluem todas as ações que precisam ser realizadas e que possam ser associadas a algum valor de negócio, para a realização do projeto visando requisitos funcionais ou não funcionais. Dessa lista são extraídas as tarefas que a equipe se comprometerá a fazer em um determinado Sprint (ciclo que tem tempo determinado - em geral de duas a quatro semanas - e contém um conjunto de atividades a serem executadas), o que é chamado de Sprint Backlog [SCHWABER e BEEDLE, 2002]. As tarefas são em geral descritas em post-its ou cartões que são fixados em um quadro contendo as divisões: "A fazer" (TO DO); "Em Execução" ou "Em Andamento" (DOING); "Feito" ou "Concluído" (DONE). Este quadro é conhecido por Quadro de Kanban (tradução do Japonês de "registro"). Ele não está presente no Scrum Guide [SUTHERLAND e SCHWABER, 2013], porém muitas equipes fazem uso do mesmo, com o objetivo de gerenciar melhor o andamento das tarefas.

Pereira et al. [2007] dizem que devem ocorrer reuniões diárias (Daily Meeting), que são encontros rápidos que acontecem todos os dias com 15 minutos ou menos de duração, cujo objetivo é observar o progresso do projeto. Ao final do Sprint devem ocorrer: uma reunião de revisão (Sprint Review Meeting), onde a equipe demonstra o produto e faz a validação para ver se o objetivo foi atingido; e a reunião de retrospectiva (Sprint Retrospective), cujo objetivo é melhorar o processo da equipe.

De forma simplificada, o Scrum funciona conforme a figura 1.

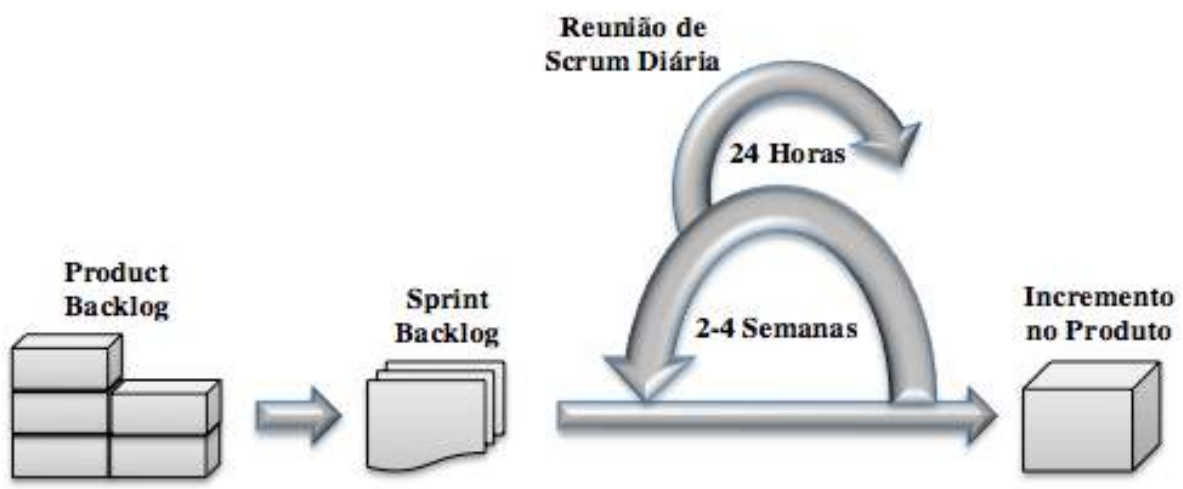

Figura 1. Ciclo do Scrum simplificado [Elaborado pelos autores]

\section{Jogos para Ensino do Scrum}

Existem diversos jogos que podem ser utilizados para o ensino dessa metodologia, de forma fácil e descontraída. O jogo apresentado nesse trabalho é não computacional e a tabela 1 ilustra alguns desses jogos utilizados para o ensino de Scrum. Os jogos não computacionais são aqueles que não necessitam do uso de computadores para seu funcionamento, podendo ser uma atividade livre, permitir ao jogador a possibilidade de repetição quantas vezes forem necessárias, ser dinâmico e possibilitar a imaginação e autonomia de quem o joga [PASSERINO, 1998]. Estes jogos são praticados em uma mesma sala, de forma que seus participantes possam interagir entre si e se adaptar às regras durante a partida, estabelecendo fronteiras e restrições [CRAWFORD, GOSLING, LIGHT, 2013]. 
As características de jogos para o ensino de Scrum foram levantadas e utilizadas para comparação dos jogos encontrados na literatura e/ou comercialmente. A legenda para leitura da tabela é: TA: uso de tabuleiro; PA: uso de papel e/ou caneta/lápis; CA: uso de cartas, cartões e/ou post-its; KA: uso de quadro Kanban; MD: uso de materiais diversos, como LEGO, por exemplo; e OF: uso de outras formas para ensino.

Tabela 1: Jogos não computacionais para o ensino de Scrum.

\begin{tabular}{|l|c|c|c|c|c|c|}
\hline \multicolumn{1}{|c|}{ Jogo/Características } & TA & PA & CA & KA & MD & OF \\
\hline Ballpoint game & & & & & Bolas & \\
\hline PlayScrum & $\mathrm{X}$ & & $\mathrm{X}$ & & Dado & \\
\hline Scrum from Hell & & & $\mathrm{X}$ & & & Dinâmica \\
\hline $\begin{array}{l}\text { Scrum Simulation with } \\
\text { LEGO Bricks }\end{array}$ & & $\mathrm{X}$ & $\mathrm{X}$ & & $\begin{array}{c}\text { Lego, } \\
\text { cronômetro }\end{array}$ & \\
\hline SCRUMIA & & $\mathrm{X}$ & $\mathrm{X}$ & $\mathrm{X}$ & Jornal & \\
\hline The Scrum LEGO Challenge & & $\mathrm{X}$ & $\mathrm{X}$ & & Lego & \\
\hline
\end{tabular}

Conforme observado na tabela 1, a maioria dos jogos faz uso de cartas, cartões ou post-its. O uso de materiais diversos é outra característica importante, sendo que em dois dos jogos são utilizados materiais de baixo custo, como bolas de ping-pong e jornal. O uso de Lego mostra que esse tipo de material pode proporcionar montagens diversas para demostrar por analogia, por exemplo, funcionalidades de um software, mas existe a limitação de ser de custo elevado e não acessível a qualquer pessoa e/ou instituição.

Em nenhum dos jogos pesquisados foi encontrado o uso de componentes eletrônicos, como leds, fios e baterias. O jogo aqui proposto vem inovar nessa questão que é derivada de práticas do Movimento Maker.

\section{Agility Scrum}

O jogo proposto (Agility Scrum) é jogado por equipes que podem ser entendidas como empresas de desenvolvimento. Em cada equipe, cada aluno/jogador assume um papel (Scrum Master ou Desenvolvedor). É escolhida também, entre todos os participantes, uma pessoa para ser o Product Owner (na aplicação aqui descrita, este papel foi desempenhado pelo professor). Dentre as tarefas do jogo, os jogadores devem lidar com: complexidade, noção de qualidade do projeto, perda de membros da equipe (demissão de funcionários, por exemplo), maturidade das pessoas envolvidas, entre outros fatores que estão ligados ao andamento de um projeto. Através desses quesitos é possível mostrar como um processo não é estático em uma organização, devendo sofrer melhorias e intervenções constantes.

Tabela 2.

Os detalhes do jogo, assim como sua preparação, podem ser observados na

Tabela 2. Detalhes e preparação para o jogo

\begin{tabular}{|c|l|}
\hline Nome do Jogo & Agility Scrum - Um jogo para o auxílio no ensino da metodologia Scrum \\
\hline Objetivo & $\begin{array}{l}\text { Mostrar de forma divertida algumas etapas da metodologia Scrum e como fatores } \\
\text { diversos podem afetar o andamento de um projeto e sua organização. Mostrar aos } \\
\text { alunos, por analogia, que seguir uma metodologia pode contribuir positivamente } \\
\text { para a geração de um produto final de melhor qualidade. }\end{array}$ \\
\hline Participantes & Grupos de quatro a seis alunos. \\
\hline Tempo & 6 minutos para execução de cada Sprint, sendo 1 minuto da reunião diária. \\
\hline
\end{tabular}




\begin{tabular}{|c|c|}
\hline $\begin{array}{l}\text { Material } \\
\text { Utilizado }\end{array}$ & $\begin{array}{l}\text { Fios diversos para fazer ligações (preferencialmente com pontas para serem fixadas } \\
\text { na prontoboard); botões para acionar os leds; baterias } 3 \mathrm{~V} \text { que irão alimentar o } \\
\text { circuito a ser construído, suporte para as baterias; leds comuns (cores: amarelo, } \\
\text { verde, vermelho); leds bicolor (podendo ser escolhidos aleatoriamente, desde que } \\
\text { tenham duas cores); capacitores de cerâmica e resistores (utilizados apenas com a } \\
\text { finalidade de confundir os participantes. Não é necessário o uso destes para a } \\
\text { montagem do circuito); prontoboard (placa utilizada para ensaio em bancadas de } \\
\text { eletrônica. Sua principal vantagem é o fato de dispensar o uso de solda para fixar os } \\
\text { componentes. Aqui será utilizada para a montagem do circuito); cartões com os } \\
\text { benefícios (utilizados para auxiliar os jogadores. Podem ser dicas, por exemplo, } \\
\text { simulando o auxílio de um profissional); cartões com as penalidades (função de } \\
\text { penalizar os jogadores, como por exemplo ficar sem um membro do grupo); cartões } \\
\text { com os Sprints (tarefas que devem ser executadas sequencialmente) e quadro de } \\
\text { Kanban (desenhado no próprio quadro da sala de aula, sendo feita uma divisão, por } \\
\text { linha, para cada equipe). }\end{array}$ \\
\hline $\begin{array}{l}\text { Custo do } \\
\text { Material }\end{array}$ & $\begin{array}{l}\text { Para realização do jogo foram utilizados } 5 \text { kits com os materiais, com um valor total } \\
\text { aproximado de } \mathrm{R} \$ 100,00 \text { (outubro de } 2016 \text { ). }\end{array}$ \\
\hline Preparação & $\begin{array}{l}\text { Imprimir e recortar os cartões de benefícios e penalidades. Estes cartões deverão ser } \\
\text { embaralhados antes do início do jogo e colocados em uma mesa na sala onde o } \\
\text { mesmo será aplicado. Para download dos cartões, acessar o link: } \\
\text { https://www.mediafire.com/folder/m23civ5s581a1/AGILITY_SCRUM_-_cartas } \\
\text { Verificar quantas equipes serão formadas e imprimir os } 5 \text { cartões para cada uma } \\
\text { delas. Cada cartão (Sprint) deverá conter uma etapa do processo a ser realizado na } \\
\text { protoboard. As tarefas são sequenciais. } \\
1^{\circ} \text { Cartão) Ligar a bateria e acrescentar um led verde, este led deverá permanecer } \\
\text { aceso. A ligação deve ser realizada no corte ao lado da bateria. } \\
2^{\circ} \text { Cartão) Acrescentar um led amarelo na corrente ao lado do led verde, os dois leds } \\
\text { devem ficar acesos. } \\
3^{\circ} \text { Cartão) Acrescentar um led vermelho e um botão. O led só pode ser aceso ao } \\
\text { acionar o botão. } \\
4^{\circ} \text { Cartão) Acrescentar um botão para acender os leds do primeiro e segundo Sprints. } \\
\text { Os leds que antes ficavam acesos, só acenderão com o acionar do botão. } \\
5^{\circ} \text { Cartão) Acrescentar um led bicolor e dois botões. Cada botão deverá acender uma } \\
\text { cor do led. }\end{array}$ \\
\hline
\end{tabular}

\subsection{Descrição}

O jogo inicia com o professor dividindo a turma em grupos de 4 a 6 alunos, dispostos em lugares distintos na sala, de modo que cada grupo não consiga ver o processo sendo executado no outro grupo. Ele deverá explicar que será aplicada uma atividade que envolverá os conceitos da metodologia ágil Scrum. Após a separação, cada grupo deverá escolher um integrante para ser o Scrum Master, que será responsável por entender todo o processo desde início e repassar à sua equipe; porém este não poderá participar da execução do projeto, deve apenas coordenar seu time.

No início, os Scrum Masters devem se reunir com o professor, a fim de que sejam passadas informações sobre o funcionamento da Prontoboard e dos componentes eletrônicos que serão utilizados. Em seguida, cada Scrum Master deve pegar o cartão do Backlog (TO DO) com o primeiro Sprint, ler o mesmo e colar no quadro de Kanban em um espaço reservado à sua equipe (DOING). Após, ele deve se direcionar para o local onde está sua equipe e aguardar a ordem para passar a tarefa. O professor deve então, dar a ordem de início e marcar o tempo de 1 min para que a tarefa seja passada à equipe pelo Scrum Master. Em seguida, será dado o tempo de 5 minutos para que a equipe faça o Sprint. 
No final de cada Sprint, o Scrum Master deve se dirigir até o Product Owner (professor) e relatar se sua equipe conseguiu realizar a tarefa. Em caso positivo, ele se dirige ao quadro de Kanban e move seu cartão com o Sprint de Em Execução (DOING) para Concluído (DONE) e avança para o próximo Sprint (retirar o cartão do próximo Sprint). Caso negativo continua no mesmo Sprint e é contado mais 1 minuto de reunião e 5 minutos de execução.

No final de cada tempo de 5 minutos dos Sprints, o Scrum Master, deve retirar uma carta do baralho, podendo ser um benefício (ajuda na realização do Sprint) ou uma penalidade (penalidade para o time). As penalidades são coisas que ocorrem na vida real como, por exemplo: demissões, funcionário que está de atestado, desentendimentos pessoais, entre outras.

A equipe vencedora será aquela que terminar todos os 5 Sprints mostrados no quadro de Kanban e, que todo o circuito construído ao longo do jogo estiver funcionando corretamente.

\subsection{Aplicação}

O jogo foi aplicado em turmas do $6^{\circ}, 7^{\circ}$ e $8^{\circ}$ períodos do Curso de Bacharelado em Sistemas de Informação da Faculdade Metodista Granbery - Juiz de Fora - MG, em outubro de 2016. Os alunos já possuíam um conhecimento prévio sobre a metodologia Scrum. A formação dos grupos foi por sorteio em todos os casos. Em um dia, o jogo foi aplicado na turma de $7^{\circ}$ e $8^{\circ}$ períodos (juntas) com 3 grupos de 6 participantes cada. Em outro dia, a aplicação foi feita na turma de $6^{\circ}$ período com 2 grupos de 4 pessoas. Em cada um dos grupos, um dos integrantes foi escolhido como Scrum Master, aleatoriamente. A idade dos participantes varia de 19 a 30 anos. Houve a participação de 3 pessoas do sexo feminino. A Figura 2 mostra os participantes durante o processo do primeiro Sprint. Os participantes que estão de pé são os Scrum Masters.

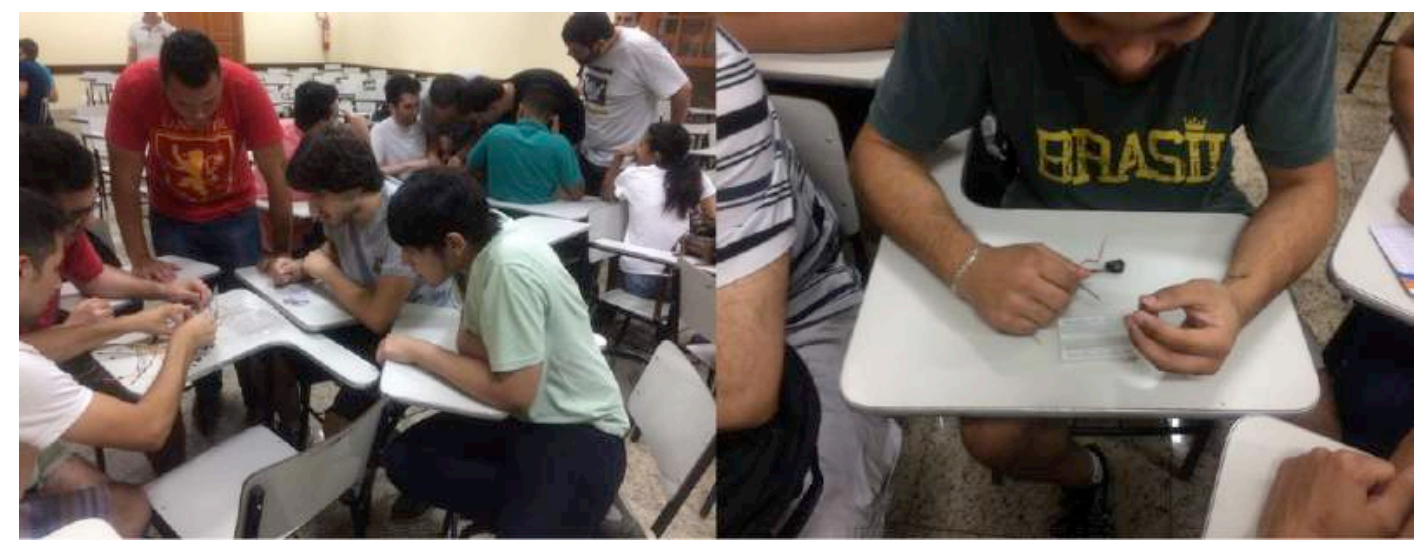

Figura 2. Participantes jogando o Agility Scrum

A Figura 3 mostra o quadro de Kanban com os Sprints sendo realizados pelos grupos, apenas um Sprint a cada execução. A divisão do quadro obedeceu as seguintes fases: "Backlog" (TO DO); "Em andamento" (DOING) e "Concluído" (DONE). Cada linha representa um dos grupos. A figura 4 mostra alguns cartões de benefícios/penalidades e a figura 5 o processo de construção de um Sprint. 


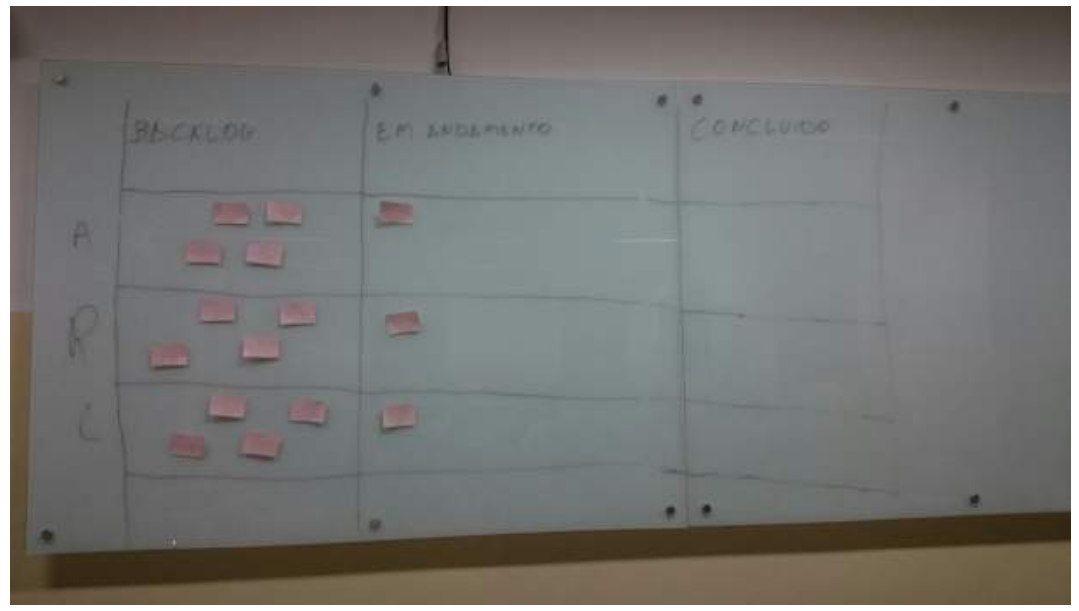

Figura 3 - Quadro de Kanban com os Sprints
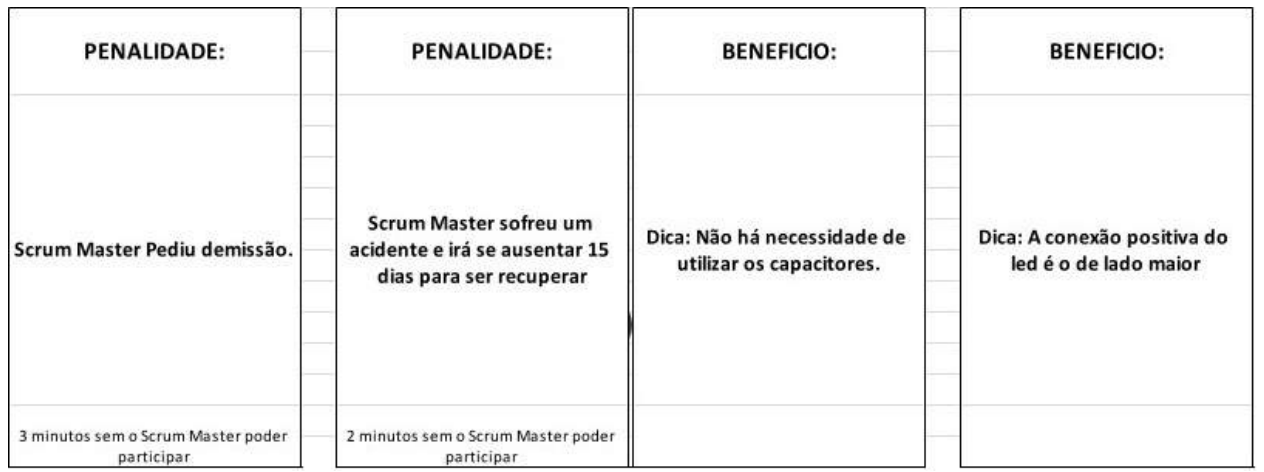

Figura 4 - Exemplos de cartões com benefícios e penalidades

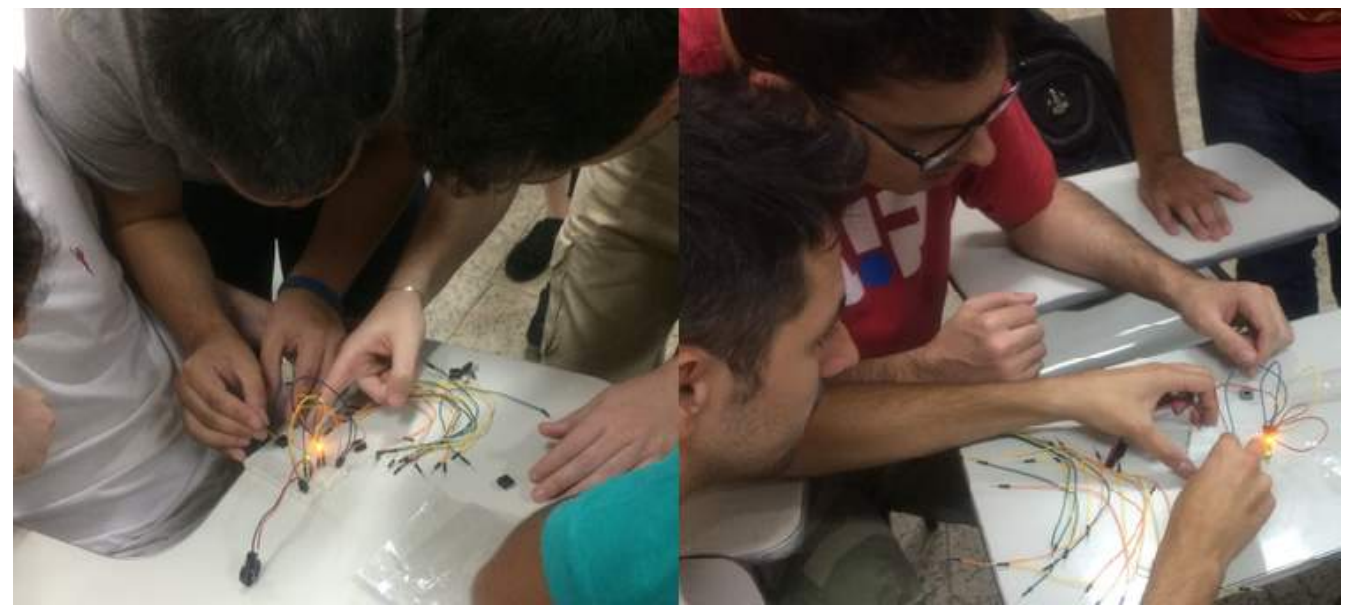

Figura 5 - Processo de construção do Sprint

\section{Resultados}

Ao final da dinâmica foi aplicado o questionário utilizado no trabalho de Castro e Souza [2016], com uma pequena modificação na questão 1 ("A dinâmica atendeu as expectativas em relação ao tema proposto: processos." alterado para "A dinâmica 
atendeu as expectativas em relação ao tema proposto: ensino da metodologia Scrum?"), contendo 25 afirmativas para coletar informações dos participantes. Cada uma delas com notas: 1 (ruim), 2 (razoável), 3 (bom), 4 (muito bom) e 5 (excelente).

O questionário teve o objetivo de verificar se, com a aplicação deste jogo, o conteúdo foi ensinado de um modo diferente; se foi possível assimilar melhor o conteúdo transmitido em relação ao método tradicional (aulas expositivas); se os alunos se sentiram motivados a estudar, utilizando artifícios diferentes do método tradicional de ensino.

O universo de alunos da pesquisa foi de 26 participantes, sendo 18 participantes em uma turma (junção de $7^{\circ}$ e $8^{\circ}$ períodos) e 8 participantes em outra ( $6^{\circ}$ período). $\mathrm{O}$ método utilizado foi de contagem de número de respostas em cada item. Após o tratamento e análise dos dados, obteve-se $82 \%$ de sucesso a partir das questões respondidas, que estão entre ter marcado a nota 4 (muito bom) ou 5 (excelente).

Mesmo com um universo restrito de participantes foi perceptível, através do desenvolvimento do processo de construção do circuito pelos grupos e da participação e motivação dos integrantes, uma melhora significativa no aprendizado. Através deste jogo também foram observados diversos benefícios como: bem estar, motivação, melhor aprendizado, aprender com erro e a dificuldade de lidar com as pessoas. Os alunos tiveram a chance de cometer erros para vivenciar uma experiência próxima ao mercado de trabalho.

O jogo mostra uma inovação no quesito material e técnica de ensino. O uso de componentes eletrônicos é uma prática derivada do Movimento Maker e muitos alunos não conheciam o funcionamento desses componentes. Diante disso, tiveram que aprender fazendo, montando o circuito passo a passo. Dúvidas foram tiradas com os Scrum Masters, que receberam orientações no início do jogo. Isso proporcionou uma experiência diferente das aulas tradicionais, com os alunos construindo o conhecimento através da prática. Este é o cerne do Movimento Maker - o Construcionismo [BLIKSTEIN e KRANNICH, 2013).

Além disso, o jogo proporcionou a vivência de algumas situações da vida real de forma simulada. Alguns grupos tiveram que lidar com penalidades como, por exemplo, ficar sem um membro durante uma rodada. Isso simula um funcionário que faltou ou está de atestado. A equipe teve que redistribuir o trabalho de forma a não ser prejudicada na realização da tarefa. Quanto aos benefícios, simulam um auxílio de um profissional mais especializado dentro da empresa. Um exemplo é "não é necessário usar os capacitores".

Alguns itens do questionário merecem destaque, como é o caso da questão 2 "Estou satisfeito com o jogo apresentado porque foi uma atividade prática diferente das aulas convencionais". Cerca de $80 \%$ dos respondentes marcou nota 5, o que leva a concluir que as aulas tradicionais, centradas em conteúdo expositivo, tendem a ser mais entediantes. O mesmo ocorreu na questão 14 - "Gostaria novamente de utilizar mais jogos e/ou formas diferentes para o aprendizado das disciplinas", com cerca de $88 \%$ dos participantes marcando nota 4 ou 5 . Isso também significa que os alunos preferem atividades lúdicas. A questão 22 - "Eu não percebi o tempo passar durante o jogo e quando vi ele acabou, ou seja, a aula passou rapidamente, mas consegui assimilar conteúdos importantes de forma agradável", com cerca de 95\% dos participantes 
marcaram nota 4 ou 5, mostra que os alunos não percebem o passar da aula quando são utilizados recursos lúdicos como recurso para o aprendizado.

No questionário havia também um espaço dedicado a comentários positivos ou negativos, que os participantes poderiam preencher conforme achassem relevantes. Cabe destacar alguns deles:

- "Deveria haver mais dinâmicas como esta. Ela nos proporcionou um maior entendimento da metodologia Scrum e uma melhor interação com os colegas";

- "Achei a dinâmica bem legal, acho que ela seria bem aplicada como introdução ao conteúdo, para posterior vir uma aplicação mais teórica utilizando a mesma como exemplo. Assim fica mais fácil fazer uma correlação no conteúdo com a vida real";

- "Achei muito interessante os desafios dados no meio do projeto, pois mostram a realidade do mercado de trabalho";

Alguns dos comentários foram negativos e devem ser levados em conta para melhorar o jogo:

- "Ficou faltando explicação de forma clara sobre as etapas do Scrum, e o Scrum Master tem que entender da regra do negócio";

- "Existem regras no Scrum que não podem deixar de ser seguidas, ainda que o Scrum seja adaptável. Senti falta dos eventos do Scrum e dos PO (Product Owner) que não existia na equipe".

\section{Conclusão}

Os alunos de hoje têm acesso a muitos recursos tais como o acesso a internet, o uso de smartphones, notebooks e muitos outros acessórios. Deste modo, é fácil perder o foco nas aulas tradicionais, em que o professor é o centro das atenções. Para evitar estas situações, é importante utilizar técnicas de ensino alternativas, como o lúdico, que auxilia, por exemplo, em disciplinas teóricas. Usar o jogo para o ensino foi uma ótima forma para fazer com que os alunos interagissem com o material proposto, ensinando-os o tema de forma prática.

O jogo Agility Scrum não tem o objetivo de mostrar de forma detalhada a metodologia Scrum, mas sim, usar uma forma prática de mostrar seus conceitos básicos saindo do ensino tradicional. Além disso, ele proporciona uma excelente interação entre os participantes, estimula a busca pelo conhecimento, visto tanto no aprendizado do Scrum, quanto em como utilizar os componentes eletrônicos. Os alunos ainda têm contato com benefícios e penalidades que simulam situações reais do cotidiano das empresas.

Como trabalhos futuros pretende-se utilizar o jogo em outras turmas e instituições. Além disso, aplicar o mesmo em turmas com alunos com idade superior a 30 anos, com o objetivo de verificar como será o comportamento dos participantes. Pretende-se também o desenvolvimento de uma versão online do jogo.

\section{Referências}

Alves A. M. P. (2009). "A história dos jogos e a constituição da cultura lúdica". Revista Linhas v. 4, n. 1. 
Battistella, P. E. and Wangenheim, C. G. V. (2016). "ENgAGED: Um Processo de Desenvolvimento de Jogos para Ensinar Computação". Simpósio Brasileiro de Informática na Educação - SBIE, Vol. 27, nº. 1.

Blikstein, P. and Krannich, D. (2013). "The makers' movement and FabLabs in education: experiences, technologies, and research". In Proceedings of the 12th international conference on interaction design and children (pp. 613-616). ACM.

Bonwell, C. C. and Eison, J. A. (1991). "Active Learning: Creating Excitement in the Classroom”. 1991 ASHE-ERIC Higher Education Reports. ERIC Clearinghouse on Higher Education, The George Washington University, One Dupont Circle, Suite 630, Washington, DC 20036-1183.

Castro, R. M. and Souza, G. S. (2016). "O Uso de Recursos Lúdicos para o Ensino de Processos em Engenharia de Software". 24 WEI - Workshop sobre Educação em Computação, XXXVI Congresso da Sociedade Brasileira de Computação, Porto Alegre.

Crawford, G., Gosling, V. K. and Light, B. (2013). "Gamers: the social and cultural significance of online games" (Vol. 56). Routledge.

Gudigantala, N. (2013). "An active learning approach to teaching undergraduate introduction to MIS Course". Paper presented at the 19th Americas Conference on Information Systems, Chicago, Illinois.

Halverson, E. R. and Sheridan, K. M. (2014). "The Maker Movement in Education". Harvard Educational Review, 84(4), 495-504,563,565.

Kahl, K., Lima M. E. O. and Gomes, I. (2007). "Alfabetização: Construindo alternativas com jogos pedagógicos”. Extensio: Revista Eletrônica de Extensão, v. 4, n. 5.

Oliveira, M. K. V. (1999). "Aprendizado e desenvolvimento, um processo sóciohistórico". 4. ed. São Paulo: Scipione, 1999.

Passerino, L. M. (1998). “Avaliação de jogos educativos computadorizados". Taller Internacional de Software Educativo 98 - TISE' 98. Anais. Santiago, Chile.

Pereira, P., Torreão, P. and Marçal, A. S. (2007). "Entendendo Scrum para gerenciar projetos de forma ágil”. Mundo PM, 1, 3-11.

Reif, H. L. and Mitri, M. (2005). "How University Professors Teach Project Management for Information Systems". Communications of the ACM, Vol. 48, no 8.

Rossiou, E. and Papadakis, S. (2007). "Educational Games in Higher Education: a case study in teaching recursive algorithms". University of Macedonia and The Hellenic Open University, 2007.

Rubin, K.S. (2012). "Essential Scrum: a practical guide to the most popular agile process". Ann Arbor: Pearson Education.

Schwaber, K. (2004). “Agile project management with Scrum”. Microsoft press.

Schwaber, K. and Beedle, M. (2002). "Agile software development with Scrum (Vol. 1)”. Upper Saddle River: Prentice Hall.

Sutherland, J. and Schwaber, K. (2013). "The scrum guide. The Definitive Guide to Scrum: The Rules of the Game". Scrum.org. 